\title{
THE RELATIONSHIP BETWEEN THE MACRO- AND MICROCLIMATE ${ }^{1}$
}

\author{
R. M. HOLMES AND A. NELSON DINGLE
}

Agrometeorological Section, Plant Research Institute, Research Branch, Department of Agriculture, Ottawa, Ont. (Canada)

Department of Meteorology and Oceanography, The University of Michigan, Ann Arbor, Mich. (U.S.A.)

(Received April 30, 1964)

\section{SUMMARY}

A search of the literature has yielded a very small number of papers dealing with quantitative relationships between the macro- and microclimate. Such relationships would be of great value in view of the difficulty in obtaining microclimatological measurements and of their limited application. It is suggested that useful relationships are possible.

\section{INTRODUCTION}

Recent impetus has been given to research concerning the relationship between biological systems and the microclimate. However, extensive and detailed microclimatological measurements have been made only for limited situations. It would be of great value if quantitative relationships could be obtained between the highly variable microclimate and the relatively homogeneous macroclimate.

There are at least two reasons why such relationships would be valuable. In the first place, a rather extensive network of macroclimatic observing stations is in existence and many years of data are available. If relationships between the microand macroclimates were established, many areas could be at least nominally categorized with regard to microclimate. Such categorization would be of value to ecologists and others interested in zonation for agricultural crops and for distribution of natural species of plants, animals, insects (microhabitats), etc. Secondly, to observe adequately the highly varied nature of the microclimate, detailed observation in both time and space is required. Thus, many specialized personnel and a prodigious instrumentation budget are required for an adequate microclimatic program.

Satisfactory relationships between macro- and microclimates should stand between the extremes of oversimplification on the one hand and excessive refinement on the other. Oversimplification is likely to be seriously misleading because of the

${ }^{1}$ Contribution No.368 from Plant Research Institute, Research Branch, Canada Department of Agriculture, Ottawa, Ont. (Canada). 
associated failure to recognize important variables. Excessive refinement is not feasib]e because of the excessive requirements of time and data. In addition, excessive refinement may introduce a large amount of non-significant data, thus complicating analysis and obscuring real relationships. It is not supposed that such relationships would eventually take the place of microclimatological measurements. On the contrary, they may serve to provide a basis for an efficient and orderly program of obtaining data where the need for greater detail is indicated.

A search of the literature reveals a host of investigations of a descriptive or observational nature. These findings suggest that useful relationships between the microclimatology of specific zones and habitats and the larger scale weather systems, regimes and events, may be determined by appropriate study. This paper presents the views of several workers to point out the feasibility of obtaining useful relationships between the macro- and microclimate.

\section{MACRO- AND MICROCLIMATE}

The macroclimate is considered to be the climate which results from the homogeneous layer of air near the ground. This layer may not extend to any great height, but within the layer little change in characteristics occurs horizontally. The macroclimate has often been referred to as that climate which is the result of the passage of air masses (Durst, 1951).

The zone of the microclimate depends on the scope of consideration but generally consists of the layer of air which is markedly altered by the surface of the earth or other surfaces thereon. The microclimate of a tree is that envelope of air surrounding the tree which acquires unique properties because of the tree. This area may extend to several meters above and beyond the tree. The microclimate of a grassy surface may be a relatively shallow layer, the depth of which would vary chiefly with wind speed and soil temperature. The microclimate of a valley in its broadest sense is the climate which results in the valley because of its special topography. Obviously no complete categorization is possible. But clearly, the scale of some microclimates can be measured in millimeters, others in centimeters, and still others in meters.

\section{MACRO- AND MICROCLIMATOLOGY}

Both before and since the time of EBERMAYER (1873) and NORDLINGER (1885), investigators have measured the climate in "confined places", such as forest glens, along streams, and in mountain valleys, etc. As a result, a rather large literature in the specialized area of forest microclimatology has accumulated and a great fund of knowledge has been gained about the variation and behaviour of climatological elements near the surface of the earth. One of the most complete compilations of results of microclimatological research is that of GeIGER $(1950,1960)$. Numerous 
references are cited to point out the complex nature of the microclimate. The behaviour of various climatological elements near the "surface of the earth" has also been summarized elsewhere (HAurwitz and AustiN, 1944; SutToN, 1953) and again by GEIGER (1951). An extensive bibliography on forest climatology and microclimatology is available in Meteorological Abstracts and Bibliographies (AMERICAN METEOROLOGICAL SoCIETY, 1957).

Many of the above authors have alluded to the rather homogeneous nature of the macroclimate as compared to the microclimate, and have suggested that they could be related quantitatively. GEIGER (1950) indicates that benefit may be derived from relating various microclimates, with a view to estimating the regime at one location from what is known about another. He observes that deviations in climate from one location to another are not random, but group themselves according to definite laws, which depend upon the physical nature of each location. He points to the possibility that these "climatological laws" might be used to obtain quantitative relationships between the microclimates of two or more locations, but it appears that this suggestion was not extended to produce such relationships. Conover (1960) studies the macro- and microclimates of an Arctic slope in Alaska, but he did not attempt to relate them quantitatively.

In more recent publications, GEJGER $(1951,1960)$ reasons that since it is impractical to measure the great variety of microclimates by building an ever increasing network of observing stations, and since the essential characteristics of similar microclimates are repeated everywhere, it suffices for many purposes to measure these characteristics at a few experimental areas and relate them to other sites within the same macroclimate. Similarly, HAURWITz and Austin (1944) indicate that typical microclimatic cases should be studied together with the properties of the "large scale or macroclimate". Such typical cases would provide a means of drawing conclusions concerning other microclimates under the same and similar macroclimatic regimes. LANDSBERG and JACOBS (1951) also suggest that advances in climatology and microclimatology are intimately related.

RiCHARDSON's work $(1953,1954,1955,1956)$ represents an effort to obtain quantitative relationships. Temperature measurements were made on the floor and east and west rims of a valley. The temperatures at these locations were studied in relation to air mass characteristics with a view to estimating microclimatic temperatures in the valley. The situation at midnight was taken as representative of conditions during the time of minimum temperature, and that at noon as representative of periods during occurrence of maximum temperature. The highest value of minimum temperature was observed on the valley floor most frequently in maritime air masses and under frontal conditions, whereas, full inversions (deepest minimum in the valley) occurred most frequently under anticyclonic conditions. Occasionally temperature differences of $14^{\circ} \mathrm{F}$ were noted during the night between the valley bottom and rim. The clear skies of anticyclonic conditions also yielded similar results with maximum temperatures. It would seem possible, if this work were extended, to forecast the temperature distribution in the valley from any given air mass forecast. 
GILBERT (1960) reports upon his efforts to measure the temperature distribution in a forest stand. The extensive temperature data already obtained and constantly being extended, are being used to study relationships between plant climates and the macroclimate as measured by the U.S. Weather Bureau. It is proposed that these studies will eventually lead to a greater predictability of the temperature pattern of plant climates from macroclimatic data.

ROBERTSON's (1953) work regarding the effective growth temperature of crops is pertinent. An attempt was made to express the effective growth temperature of small plots of millet in terms of macroclimatic factors. The results were expressed in an equation which permitted the prediction of crop temperature, viz.:

$$
t_{c}=t_{a}+\frac{0.18\left(R_{n}-H_{e}\right)}{1+0.01 U}
$$

where $t_{c}=$ crop temperature, $t_{a}=$ air temperature in macroclimate, $H_{e}=$ heat used for evapotranspiration, $R_{n}=$ net radiation over crop, $U=$ wind speed.

The coefficient, 0.18 , was dependent on certain physical characteristics of the crop (density, specific heat, etc.). Results indicated that the effective crop growing temperature averaged $4.5^{\circ} \mathrm{F}$ higher than temperature measured in a standard screen. The equation permitted the calculation of daily values of effective crop temperature which range from 2 below to $15^{\circ} \mathrm{F}$ above standard air temperature.

CARSON (1961) studied certain atmospheric factors in relation to soil temperature and related them qualitatively. He found that the multiple regression analysis of the 24-h change of soil temperature at $1 \mathrm{~cm}$ was significant and positively correlated with (1) the diurnal temperature variation in the air, (2) the changes in insolation and vapor pressure from one day to the next, (3) the air-soil temperature difference. The diurnal change of soil temperature at $1 \mathrm{~cm}$ was negatively correlated with wind speed and the temperature gradient in the soil. Only three variables, viz., diurnal temperature variation in the air, change in vapor pressure of air and heat flux in the soil yielded significant partial regression coefficients in the seasons studied. The linear correlation between the 24-h changes of air and soil temperature accounted for $60 \%$ of the variance in the soil. The inclusion of six other variables accounted for $16 \%$ more of the variance.

Ramdas of India studied the correlation between the maxima and minima in a "macro"- and "micro"-environment (RAMdas and KalamKat, 1935). He found a high degree of correlation during periods of the minimum because of calm stratified air layers. However, correlations between the maxima were not highly significant because of daytime heating and turbulence.

A field of effort which may have promising applications in a macro-microclimatic relationship concerns the study of air masses. It would be of particular advantage to relate certain climatological factors measured in macro- and microclimates to the air mass characteristics. It should be possible to concentrate on characteristics of air masses which frequent the particular area(s). Special difficulty may be experienced during the passage of fronts, consequently one should first focus on conditions 
that occur within the air mass. For example, polar continental air is cold and dry and tropical continental air is likely to be warm and moist. Therefore any given micromacroclimate relationship is likely to apply consistantly during the passage of any single air mass. Attention is called to the effect of vertical motion in anticyclones and the effect of these motions at the surface, since the influence of atmospheric stability is generally felt in all phases of the microclimate (RICHARDSON, 1953, 1954, 1955, 1956). DURST (1951) has reviewed some of the properties of air masses originating in various source areas. He cites the work of Dinies and others who have tabulated the characteristics of various air masses. BELASCO (1952) studied and classified air masses that reach the British Isles. All of these studies may aid the climatologist by providing "normal" properties of air masses.

\section{RELATING MACRO- AND MICROCLIMATES}

Our search of the literature has shown there are three broad approaches to relating macro- and microclimates: analog method, correlation techniques and physicalmodel building.

\section{Analog or direct comparison method}

Some of the work done in the early stages of microclimatology is typical of this approach (work cited in GeIGER, 1950). It is assumed that phenomena observed at location $A$ may also be observed at $B$ if the situation as regards radiation, shade, ground slope, moisture, etc. is similar at $A$ and $B$. Further if there is a consistent relationship involving soil moisture, for example, between location $A$, which is measured in the macroclimate, and microclimatological station $B$, there will also be a similar relationship between $A$ and $C$ provided the microenvironment at $C$ is similar to $B$. Comparisons by this method are nearly always made on a qualitative basis.

\section{Correlation techniques}

Correlation techniques can be used to determine the degree of dependence of microclimatic parameters on factors of the macroclimate. Further, the degree of association between one variable in a microenvironment and a factor of the macroclimate, independent of the effect of other variables can be estimated through multiple and partial regression and correlation techniques.

These methods produce empirical relationships where linearity can be assumed. Occasionally, however, they are products of the "let's see if this works", attitude. Such expressions of dependence of one variable on another do not elucidate the underlying principles, and are useful under only very limited conditions. Therefore, caution must be exercised before cause and effect relationships between two variables are assumed, even though statistical significance is obtained. 
On the other hand, it may be a mistake to reject a statistically insignificant correlation before the presence of causes and effects is thoroughly tested. In truth, a cause and effect relationship may be known to exist but may be masked by other factors.

A problem involving related variables, often can be simulated by a mathematical model which utilizes certain basic principles (HOLMES and ROBERTSON, 1959; ROBERTSON and HolmEs, 1956). When the theory is understood and the model constructed, it can be tested for linearity via correlation procedures. The method weights the factors involved in the expression according to the degree of linearity. Non-linear data must either be linearized to conform to theory, or another approach must be taken which does not rely on linearity.

\section{Physical model building techniques}

Properly constructed mathematical-physical models that describe known cause and effect relationships can be used in relating macro- and microclimates. De Vries used this approach in a study of the effect of irrigation on the climate of a pasture (DE VRIES and BIRCH, 1951; DE VRIES, 1959). The physical principles involved were described quantitatively and this made it possible to calculate the energy balance, the temperature and humidity regimes of the irrigated area from meteorological data taken at a "dry" station.

The parallel here is obvious: physical principles can be used to construct models for computing microclimatic factors from macrometeorological data. It is futile to frame models for each of the many macro-micro combinations of soil, plants, and atmosphere. A more fruitful approach is to examine plant vegetation, etc., as regards density of stems and leaves, radiativity, resistance to wind flow, canopy volume, transpiration rate, etc., so that all plant species are included under a single broad scheme. Similarly, to assign special properties to each of the various soil types would be very cumbersome, whereas a system which describes all soils in physical terms such as heat content and conductivity, reflectivity, roughness, moisture content, elc.. simplifies the problem. Perhaps, not all of the physical characteristics of the interface would find a place in an adequate model. As mentioned earlier, unwarranted refinement and possible over-complexity would result.

\section{CONCLUSION}

The benefits to be derived from work in the area of relating macro- and microclimates are numerous. Although this fact is widely acknowledged, few attempts have been made to state the problem past the point of random thought. In the above, the authors have tried to bring the factors involved in relating macro- and microclimates into clearer focus. 


\section{REFERENCES}

American Meteorological Society, 1957. Meteorol. Abstr. Bibliog., 8 (4) : 515-539.

Baum, W. A. and Court, A., 1949. Research status and needs in microclimatology. Trans. Am. Geophys. Union, $30: 488-493$.

Belasco, J. E., 1952. Characteristics of air masses over the British Isles. Geophys. Mem. Meteorol. Office, $87: 34 \mathrm{pp}$.

Brooks, C. K. P. and Carruthers, R., 1953. Handbook of Statistical Methods in Meteorology. H. M. Stationery Office, London, $412 \mathrm{pp}$.

Carson, J. E., 1961. Soil temperature and weather conditions. Argonne Natl. Lab., Argonne, Ill., Rept. ANL-6470, $127 \mathrm{pp}$.

Conover, J. W., 1960. Macro- and microclimatology of the arctic slope of Alaska. U.S. Army, H.Q.R. and E.C., Natick, Mass., Tech. Rept. EP-139, 62 pp.

CoUrt, A., 1949. Separating frequency distributions into two normal components. Science, 110 : 500-501.

DE VRIES, D. A., 1959. The influence of irrigation on the energy balance and the climate near the ground. J. Meteorol., $16: 256-270$.

DE VRIEs, D. A. and Birch, J. W., 1951. The modification of climate near the ground by irrigation for pastures on the Riverine Plain. Australian J. Agr. Res., 12 : 260-272.

Durst, C. S., 1951. Climate synthesis of weather. In: T. F. Malone (Editor), Compendium of Meteorology. Am. Meteorol. Soc., pp. 967-975.

Ebermayer, E. W. F., 1873. Physical Effects of Forests on Air and Soil and their Climatological and Hygienic Importance. Krebs, Aschaffenburg, $266 \mathrm{pp.}$

Geiger, R., 1950. The Climate near the Ground. Brunswick, Vienna, 482 pp. 2 ed.: 1957, Cambridge Univ. Press, London, $492 \mathrm{pp}$.

Geiger, R., 1951. Microclimatology. In: T. F. Malone (Editor), Compendium of Meteorology. Am. Meteorol. Soc., pp. 993-1003.

GeIGER, R., 1960. Klima der Bodennahen Luftschicht, 4. Aufl. Brunswick, Vienna, 646 pp.

Gilbert, G. E., 1960. Forest climate knowledge broadened at Ohio State. Mod. Precision, 20 (1) : 1-7.

Gumbel, E. F., 1949. Probability tables the range. Biometrica, $36: 142-148$.

Haurwitz, B. and Austin, J. M., 1944. Climatology. McGraw-Hill, New York, N.Y., 410 pp.

Holmes, R. M. and Robertson, G. W., 1959. Heat units and crop growth. Can. Dept. Agr., Bull., $1042: 31 \mathrm{pp}$.

Landsberg, H. E. and Jacobs, W., 1951. Applied climatology. In: T. F. Malone (Editor), Compendium of Meteorology. Am. Meteorol. Soc., pp. 976-992.

Nordlinger, T., 1885. Influence of the Forest upon Air and Soil Temperature. Parey, Berlin, $100 \mathrm{pp}$.

Panofsky, H. A. and Brier, G. W., 1958. Some Applications of Statistics to Meteorology. Penn. State Univ., Coll. Mineral Ind., 224 pp.

Ramdas, L. A. and Kalamkat, R. J., 1935. Studies in microclimatology. 2. Indian J. Agr. Sci., 5 (1) : $1-11$.

Richardson, W. E., 1953. "Remarkable" sizes in temperature. Meteorol. Mag., 82 (978) : $374-375$.

Richardson, W. E., 1954. Temperature differences in the South Tyne Valley near Alston, Cumberland. Weather, 9 (3) : 82-85.

RichardSON, W. E., 1955. Night cooling under clear skies at high level stations in Cumberland. Meteorol. Mag., $84(1000): 301-304$.

Richardson, W. E., 1956. Temperature differences in the South Tyne Valley, with special reference to the effects of air mass. Quart. J. Roy. Meteorol. Soc., $82: 342-348$.

Robertson, G. W., 1953. Some agrometeorological problems in Canada. Roy. Meteorol. Soc., Can. Branch, 4 (2) : 5-11.

Robertson, G. W. and Holmes, R. M., 1956. Plant-climate relationships in Canada. Natl. Workshop Agrometeorol., 1st, Madison, Wisc., 1956, 10 pp., unpublished.

Roble, A. D., 1937. Comparison of temperature from roof and ground exposures at Topeka, Kansas, 1935-1936. Monthly Weather Rev., $65: 388-392$.

SutTon, O. G., 1953. Microclimatology. McGraw-Hill, New York, N.Y., 333 pp. 